\title{
Ecologization and digitalization of preschool education for sustainable development: problems and prospects
}

\author{
Maria Vilacheva*, Mariia Zadorina, and Veronika Meshcheryagina \\ Ural State University of Economics, 8 Marta / Narodnoy Voli Str., 62/45, 620144 Ekaterinburg, \\ Russia
}

\begin{abstract}
The paper is devoted to the problems of modernization of the preschool education in Russia. The general scientific and private scientific methods formed the methodological basis of the research. There are two directions in the development of the Russian education system over the past few years: ecologization and digitalization. The ideas of the "green economy" are actively entering the field of education. The federal state educational standards provide the opportunity of forming the basics of children's ecological literacy, ecological culture and ecological intellection in schools, but not in preschool educational organizations. The process of digital transformation is more focused on school and colleges and less on kindergartens. These problems slow down the pace of sustainable development because preschool education is the foundation of a child's personal development in the future. This paper presents the promising directions for improving the preschool educational system for sustainable development.
\end{abstract}

\section{Introduction}

It is impossible to imagine sustainable development without a harmonious relationship between the authorities and citizens. On the one hand, the state should create conditions for the comprehensive personal development, improving the well-being and quality of life of the population, and ensuring the safety of each person. On the other hand, such state activities will not be effective if the population of the country does not improve its legal awareness, receive high-quality education, develop culture, take care of nature, and contribute to the social and economic development of the country. In this regard, the state needs constantly improve the education system.

For several years, digitalization has been one of the key directions of development of the education system in Russia. The process of introducing digital learning technologies is quite successful at the level of professional education. There are many problems at the level of general education that have a negative impact on the digital transformation of education in schools and, in particular, in preschool educational organizations.

\footnotetext{
"Corresponding author: vilacheva.m@yandex.ru
} 
Another direction of development of Russian education in recent years is its "ecologization" - the penetration of ideas and concepts of sustainable development, environmental protection, and lean manufacturing into the educational process. The ecological education system covers almost all types and levels of education (including general education) now. However, the formation of children's ecological culture and ecological intellection within this type of education is provided only in schools, but not in preschool educational organizations.

These trends keep the rate of sustainable development of the Russian economy and need to be researched.

\section{Materials and Methods}

The methodological basis of the study is general scientific (analysis, synthesis, comparison, induction, deduction, structural-functional method) and specific scientific methods (formallegal, formal-logical).

Material for research: the Constitution and other regulatory legal acts of the Russian Federation, scientific articles by Russian and foreign authors, analytical data of the authorities.

\section{Results and Discussion}

The fundamental principles of legal regulation of the field of preschool education in the Russian Federation are based on the norms of Part 2 of Article 43 of the Constitution of the Russian Federation, which guarantees the general availability and free of charge of preschool education in state or municipal educational organizations and enterprises. At the same time, Article 42 of the Russian Constitution establishes the right of everyone to a favorable environment. Thus, the Russia like a social state, undertakes to fully ensure the implementation of these rights, including the sustainable development.

Ecologization of preschool education. The Constitution of the Russian Federation in Part 1 of Article 21, enshrined the right to life - the possibility of a decent and prosperous existence for everyone [1]. One should consider the fact that a decent and prosperous human existence depends on many factors, including the environment. In accordance with Article 3 of Federal Law No. 7-FL of January 10, 2002 "On Environmental Protection", one of the principles of environmental protection is the organization and development of the system of ecological education, formation of ecological culture.

Ecological education is a "purposefully organized, systematic and continuous process of having ecological knowledge, skills and abilities, the formation of a general ecological culture" [2]. It is aimed at creating "a respectful attitude towards nature in the interests of sustainable development" [3].

The system of ecological education in Russia includes general education, secondary vocational education, higher education and additional professional education of specialists, as well as the dissemination of ecological knowledge, including through the media, museums, libraries, cultural institutions, environmental institutions, sports and tourism organizations (Article 71 of Federal Law No. 7-FL of January 10, 2002 "On Environmental Protection"). For example, "educating ecological and information culture has been growing into a new relevant function of the libraries" all over the world [4].

It is necessary to note, that general education is divided into levels in Russia: preschool education (kindergarten), primary general education (grades 1-4 of school), basic general education (grades 5-9 of school) and secondary general education (grades 10-11 of school). The dissemination of ecological knowledge at each of these levels of education must be 
carried out in strict accordance with the provisions of the federal state educational standards. Thus, a child should form primary ideas about the objects of the environment, ideas about the social and cultural values of the Russian people, about domestic traditions and holidays, about the planet Earth as a common home of people, about the peculiarities of its nature within the framework of preschool education. Children are taught the basics of ecological literacy in the course of primary education. The emphasis of basic general education is placed on the formation of the foundations of ecological culture. Children should develop an ecological intellection as a result of receiving secondary general education. As you can see, less attention is paid to ecological education in kindergartens. Moreover, "in most educational organizations, the solution to the problems of educating ecological culture still remains at the level of declarations" [5].

At the same time, it is well-known that one of the most important components in the formation of an individual as a person is played by the attitudes that are laid down in him from early childhood. A significant role in the formation of these prerequisites and factors is played by preschool education as an integral stage of human educational development. It is generally accepted that preschool age is the age of accelerated physical and mental development of a child, the formation of skills and abilities that determine his physical, intellectual, and mental development in the future. In this regard, the ecologization of preschool education in the Russian Federation should be given more attention, taking into account the experience of working with preschoolers acquired during the «Soviet period» of Russian history, as well as taking into account promising practices applied in most foreign countries where state programs for early childhood development are implemented. It is necessary for the sustainable development of the economy, the formation of a full and active participant in civil society, a qualified employee, an ecologically competent and responsible citizen of their state. For example, in many countries the implementation of ecological education into the national education system includes competitions, didactic visits and trips [6], ecological gardens [7]. A similar practice can be implemented in Russian preschool educational organizations.

There is a need to revise the federal state educational standard for preschool education. Preschool education should give the child primary knowledge about the ecology, about the basic rules of waste treatment, introduce the basic rules of ecologically safe behavior on water, in the forest, parks, etc.

Digitalization of preschool education. The Government is tasked with creating a modern and secure digital educational environment that ensures high quality and accessibility of education of all types and levels by Decree of the President of the Russian Federation No. 204 of May 07, 2018 "On National Goals and Strategic Objectives for the development of the Russian Federation for the period up to 2024".

In 2019, the Ministry of Education of the Russian Federation developed a Model of the Digital Educational Environment. However, it is more focused on the development of the digital environment in schools than in preschool educational organizations. The school is the next link in the level of education of the child. It is obvious that preschool education faces the issues of expanding the educational space of preschool education of children: distance and mixed learning, combined, additional, virtual reality; updating the content of preschool education of children with modern digital technologies; digitalization of the assessment of the quality of education as a state (municipal) service.

In the system of general and higher education, within the framework of the project "Modern Digital Educational Environment in the Russian Federation", online platforms have already been created and are being developed (for example, the national open education platform "openedu.ru", the network interuniversity platform for electronic online education "Universarium", the open video archive of lectures for teaching in Russian 
"Lectorium"). "The use and construction of these platforms is a reality in continuous expansion, now enhanced by the pandemic, due to the need for physical isolation" [8].

However, these platforms are either not used at the level of preschool education, or simply are not adapted to this level of education. However, the use of digital technologies at each level of education increases the overall effectiveness of educational activities when these technologies become publicly available to all participants in educational relations, regardless of the level of education received. At the same time, it is important to note that only equipping educational organizations with information and communication technologies does not involve an increase in the effectiveness of the learning process, these measures should be accompanied by the simultaneous introduction of new content, forms and methods of educational, organizational and methodological work into the educational environment.

It is worth noting that the implementation of the constitutional right to preschool education in Russia directly depends on the effectiveness of the activities of local selfgovernment bodies (Paragraph 1 of Part 1 of Article 9 of Federal Law No. 273-FL of December 29, 2012 "On Education in the Russian Federation").

Nowadays parents (legal representatives of children) fill out an application in electronic form on the Official Internet Portal of public services (https://www.gosuslugi.ru/) for admission to kindergartens. They select up to 3 desired preschool educational organizations at the child's place of residence in application. But in practice, children do not always get places in those kindergartens that their parents (legal representatives) indicated in the application. For example, you can get a place in a kindergarten located far from the child's place of residence or even in another locality. In such cases the parents or legal representatives (if they did not specify this kindergarten in the application) can send an appeal to the local authorities with a request to transfer their child to another preschool educational organization. However, such appeals do not always form a separate shared registry, nor do they form a queue. As a result, the appeals are considered not in the order of priority, but in a chaotic order. In this situation, the constitutional principle of equality is violated, which is unacceptable in the social legal state like Russia.

Besides, the digitalization of preschool education also implies the possibility of obtaining preschool education in a distance form. However, this practice is not widespread in Russia today. All the activities of educators are aimed exclusively to contact (direct) work with children, excluding the distance format of interaction between the educator and children. There is no demand for the services of kindergartens and nurseries in the online format. The reason is the fact that the process of interaction between the educator and the child online involves the presence of another person who is responsible for the supervision and care of the child. This can be a parent, a legal representative, a relative, a nanny, etc. However, in many cases parents work, there may not be relatives who would be able to look after the children, and also there is not always money to pay for the services of nannies.

In addition, the process of digitalization also affected the subsequent assessment of the quality of the provision of preschool education as a type of municipal service. At present, the institute for assessment of the quality of the provision of state and municipal services has not received proper legal regulation, although the first practical prerequisites have been embodied in the framework of the portal «Your Control» (https://vashkontrol.ru/), where citizens of the Russian Federation can leave their comments on the activities of a government body and a specific official. However, such comments do not involve legal consequences for the authorities and officials (both positive and negative legal liability). All this reduces the desire for the widespread use of digital technologies in the activities of Russian municipalities, the possibility of an objective assessment of the effectiveness of the implementation of individual management technologies for providing services. 


\section{Conclusions}

1. People's interest in the problems of ecology and environmental protection throughout their life depends on preschool's behavioral patterns and knowledges about the environment. The state can create the necessary conditions for sustainable development in the future by paying attention to the education of ecological culture in preschool children organization. However, for this purpose, the federal state educational standard for preschool education should be revised, the list of targets for preschool education should be supplemented, and the list of used means and methods of teaching should be expanded.

2. The creation of the filtering systems for appeals to local governments about the transfer of children from one preschool educational organization to another is a promising direction of digitalization of preschool education. As a result, such appeals will be included in the unified register and considered in the order of priority. This will make the activities of local self-government bodies to organize the provision of public and free preschool education more effective and transparent.

3. The state multifunctional centers have been more successful in organizing of monitoring of the quality and availability of public services. Municipalities either do not organize an assessment of the quality of municipal services, or they conduct it at their own discretion. In this regard, it makes sense at the legislative level to unify the process of monitoring the quality and availability of municipal services, to bring it to a single denominator. It is also necessary to provide the possibility of evaluating municipal services in order to summarize data on the satisfaction of citizens with the processes of providing services.

The practice of the portal «Your Control» clearly shows that the authorities do not understand the legal nature of comments and do not know how to respond to them. At the same time, the concept of electronic comments on the quality of the provision of services in the field of preschool education has significant potential. Competent organization of work with them, provided that they are widespread, will allow the authorities to receive objective information about problematic or, conversely, positive aspects in the activities of the authorities and their officials. The organization of the institute of comments using the traditional paper form is unpromising, will not provide mass comments, will be ineffective and will increase the burden on officials.

\section{References}

1. I. Kh. Babadzhanov, E. M. Ol, Bulletin of the Academy of Economic Security of the Ministry of Internal Affairs of Russia, 11, 43 (2010)

2. E. A. Khachatryan, Scientific notes of the Kazan State Academy of Veterinary Medicine named after N. E. Bauman, 221(1), 234 (2015)

3. O. V. Zakharova, L. G. Suvorova, M. V. Bogdanova, A. V. Zakharov, A. Permyakov, I. Y. Malykh, Sustainability, 13(7), 4040 (2021)

4. E. F. Bychkova, Nauchnye i tekhnicheskie biblioteki-scientific and technical libraries, 5, 85 (2020)

5. M. N. Silantiev, E. I. Sharova, M. N. Kurochkina, F. M. Ordokova, G. A. Kyarova, International Journal of Educational Sciences, 31(1-3), 61 (2020)

6. M. Botea, EDU World 2018 - 8th International Conference, 67, 1708 (2019)

7. L. Aragon, S. Sanchez, J. M. Enriquez, Revista Eureka Sobre Ensenanza y Divulgacion de las Ciencias, 18(1), 1103 (2021) 
8. E. Schlemmer, M. Di Felice, Revista Latinoamericana de tecnologia educativa-Relatec, 19(2), 207 (2020) 